\title{
Isolation and identification of a phytotoxic substance from the emergent macrophyte Centrostachys aquatica
}

Tran Thi Ngoc Bich ${ }^{1,2}$ and Hisashi Kato-Noguchi ${ }^{*^{*}}$

\begin{abstract}
Background: Centrostachys aquatica is a perennial emergent macrophyte in marshy places and in rivers. The species was recorded in Senegal and Nigeria, but widespread in tropical Africa, and South and East Asia. Aqueous methanol extracts C. aquatica was found to be toxic to several plant species. However, no phytotoxic substance has been reported in this species. Therefore, we investigated phytotoxic activity and searched for phytotoxic substances with allelopathic activity in C. aquatica.
\end{abstract}

Results: An aqueous methanol extract of $C$. aquatica inhibited the growth of roots and hypocotyls of cress (Lepidium sativum). The extract was then purified by several chromatographic runs and a phytotoxic substance with allelopathic activity was isolated and identified by spectral analysis as loliolide. Loliolide inhibited cress root and hypocotyl growth at concentrations greater than $0.03 \mu \mathrm{M}$. The concentrations required for $50 \%$ growth inhibition of cress roots and hypocotyls was 0.18 and $0.15 \mu \mathrm{M}$, respectively.

Conclusion: These results suggest that loliolide is a phytotoxic substance and may contribute to the allelopathic effect caused by C. aquatica.

Keywords: Allelopathy; Bioactive substance; Centrostachys aquatica; Loliolide, Macrophyte; Phytotoxicity

\section{Background}

Centrostachys aquatica (R.Br.). Wall ex Moq Tand (Synonym, Achyranthes aquatica R.Br; Amaranthaceae) is a perennial emergent macrophyte with $0.3-1.5 \mathrm{~m}$ stem in length and rooting at nodes forming meadows in marshy places and in rivers. The species was recorded from Senegal and Nigeria, but widespread in tropical Africa, and South and East Asia including India (Baker 1913; Townsend 1988).

Many exotic plants naturalized in invasive areas due to their special life-history traits, such as high rate of growth and reproduction, and phenotypic plasticity (Mack 1996; Cappuccino and Arnason 2006). High defense capacity of the invasive plants against pathogens and herbivores is also very critical in the new habitats

\footnotetext{
* Correspondence: hisashi@ag.kagawa-u.ac.jp

${ }^{1}$ Department of Applied Biological Science, Faculty of Agriculture, Kagawa University, Miki, Kagawa 761-0795, Japan

Full list of author information is available at the end of the article
}

(Keane and Crawley 2002; Mitchell and Power 2003; Cappuccino and Carpenter 2005). In addition, some invasive plants contain large amounts of phytotoxic and/or allelopathic substances, which are toxic to native plant species in the invasive areas (Callaway and Ridenour 2004; Chengxu et al. 2011). Centaures maculosa releases an allelopathic substance, catechin, which makes its invasion into the new habitats (Callaway and Aschehoug 2000). Thus, the production of allelopathic and phytotoxic substances may be one of the important traits for invasive plants for the new habitats (Meiners et al. 2012).

It was also reported that aqueous methanol extracts of C. aquatica were toxic to several plant species and shown allelopathic activity (Bich and Kato-Noguchi 2012). The findings suggest that $C$. aquatica may contain phytotoxic substances with allelopathic activity. However, no such substance has been reported in $C$. aquatica so far. The objective of this study was the isolation and identification of phytotoxic substances with allelopathic activity in this species. 


\section{Methods}

\section{Plant materials}

Whole plants of Censtrotachys aquatica (R.Br.) Wall ex Moq Tand were collected from riversides, in Ô môn district, Cần Thơ City, South of Vietnam $\left(9^{\circ} 27^{\prime} \mathrm{N}, 106^{\circ} \mathrm{E}\right)$, in January of 2012 (dry season), washed with tap water and dried under sunlight. Dry materials were then packed and protected from air humidity by a silica gel desiccant and stored at $3^{\circ} \mathrm{C}$ until extraction. Cress (Lepidum sativum L.), obtained from Takii Co. (Kyoto, Japan), was chosen as a test plant for the bioassays due to their known seedling growth behavior.

\section{Extraction}

Dried plants of C. aquatica (300 g) were soaked in $1.5 \mathrm{~L}$ of $70 \%(\mathrm{v} / \mathrm{v})$ aqueous methanol for two days. After filtration using filter paper (No. 2; Toyo, Tokyo, Japan), the residue was soaked again in $500 \mathrm{~mL}$ methanol for two days and filtered, and the two filtrates were combined. An aliquot of the extract (final assay concentration of tested samples corresponded to the extracts obtained from $0.01,0.03,0.1$ and $3 \mathrm{~g}$ dry weight of $C$. aquatica per $\mathrm{mL}$ ) was evaporated to dryness and biological activity of the extracts was determined by a cress bioassay as described latter.

\section{Separation of the aqueous methanol extract}

Dried plants of $C$. aquatica were extracted as described above. The two filtrates were combined and concentrated at $40^{\circ} \mathrm{C}$ in vacuo to produce an aqueous residue. The aqueous residue was then adjusted to $\mathrm{pH} 7.0$ with $1 \mathrm{M}$ phosphate buffer, partitioned three times against an equal volume of ethyl acetate, and separated ethyl acetate and aqueous phase. The biological activity of the aqueous and ethyl acetate fractions was determined using a cress bioassay as described latter.

\section{Isolation of active substance in ethyl acetate fraction}

The ethyl acetate fraction was evaporated to dryness and separated on a column of silica gel (80 g, silica gel 60 , 70-230 mesh; Merck), eluted with 20, 30, 40, 50, 60, 70 and $80 \%$ ethyl acetate in $n$-hexane (100 mL per step), ethyl acetate $(100 \mathrm{~mL})$ and methanol $(200 \mathrm{~mL})$. The biological activity of all separated fractions was determined using a cress bioassay as described latter, and the most active fraction was obtained by elution with $70 \%$ ethyl acetate in $n$-hexane.

After evaporation of the most active fraction, the residue was purified by a column of Sephadex LH-20 (60 g, Amersham Pharmacia Biotech, Buckinghamshire, UK), and eluted with 10, 20, 30, 40, 60 and $80 \%$ (v/v) aqueous methanol (100 mL per step), and methanol (200 mL). The active fraction was eluted by $30 \%$ aqueous methanol. After evaporation, the residue was dissolved in $20 \%$ $(\mathrm{v} / \mathrm{v})$ aqueous methanol $(2 \mathrm{~mL})$ and loaded onto reversephase $\mathrm{C}_{18}$ cartridges (YMC Ltd., Kyoto, Japan). The cartridge was eluted with $20,40,60,80$ and $90 \%$ (v/v) aqueous methanol, and methanol (15 mL per step). The active fraction was eluted by $80 \%$ aqueous methanol and evaporated to dryness. The residue was finally purified by reversephase HPLC $(10 \mathrm{~mm}$ ID $\times 500 \mathrm{~mm}$; YMC- Pack ODS AQ-325; YMC Ltd.) eluted at flow rate of $1.5 \mathrm{~mL} \mathrm{~min} \mathrm{~m}^{-1}$ with $40 \%$ aqueous methanol and detected at $220 \mathrm{~nm}$. The inhibitory activity was detected at a peak of $162-172 \mathrm{~min}$, yielding active compound as colorless oil. The compound was characterized by HRESIMS, ${ }^{1} \mathrm{H}$-NMR spectrum $\left(400 \mathrm{MHz}, \mathrm{CD}_{3} \mathrm{OD}\right)$ and the specific rotation.

\section{Cress bioassay for C. aquatica extract and HPLC-purified compound}

Test samples (aqueous methanol extracts and a purified compound) were dissolved in a $0.2 \mathrm{~mL}$ of methanol and added to a sheet of filter paper (No. 2) in a 3-cm Petri dish. The methanol was evaporated in a fume hood. Then, the filter paper in the Petri dishes was moistened with $0.8 \mathrm{~mL}$ of $0.05 \%(\mathrm{v} / \mathrm{v})$ polyoxyethylene sorbitan monolaurate (Tween 20). Ten seeds of cress were placed in the Petri dishes. The length of roots and hypocotyls of the seedlings were measured after $48 \mathrm{~h}$ of incubation in the darkness at $25^{\circ} \mathrm{C}$, and compared to control seedlings. Controls were treated exactly as described above, with the exception that $0.2 \mathrm{~mL}$ methanol was used instead of $C$. aquatica extract or isolated compound. The bioassay was repeated three times using a randomized design with 10 plants for each determination. Significant differences between control and treatment were examined by Welch's $t$-test. Significant differences among treatments were examined by Duncan's multiple comparison tests.

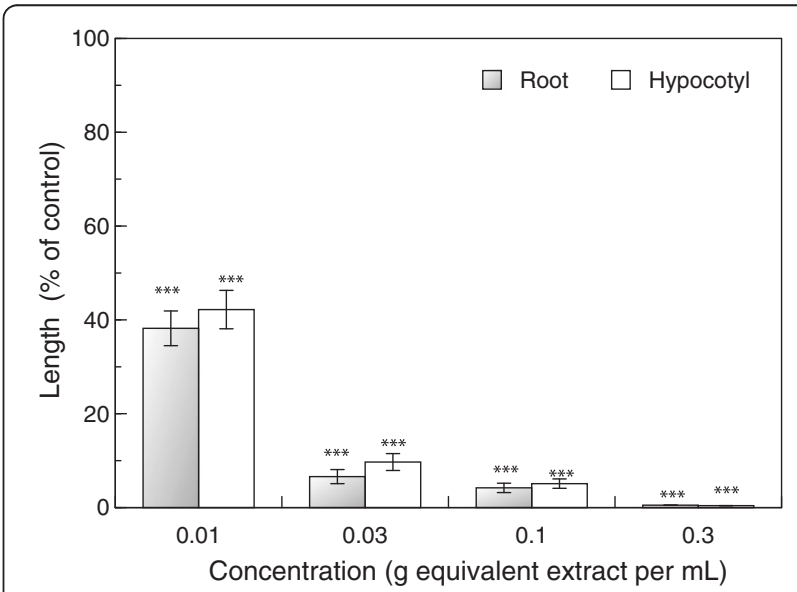

Figure 1 Effects of aqueous methanol extracts of $C$. aquatica on root and hypocotyl growth of cress. Asterisks indicate significant difference between control and treatment: ${ }^{* *}, \mathrm{P}<0.001$. 


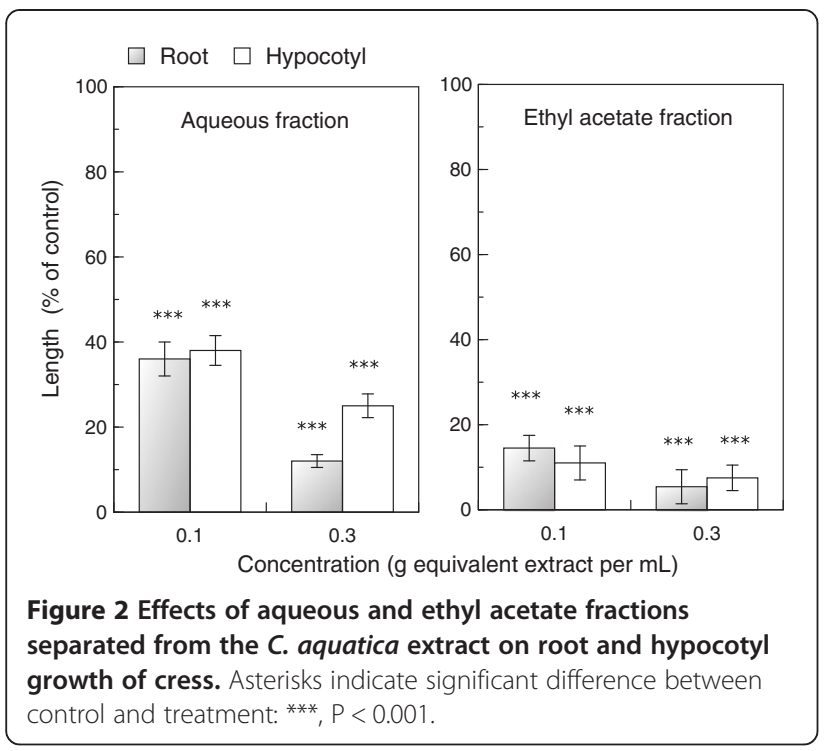

Results and discussion

Inhibitory activity of the extract of C. aquatica and separation

The aqueous methanol extract of $C$. aquatica inhibited root and hypocotyl growth of cress seedlings. Increasing the extract concentration resulted in an increase in the inhibition (Figure 1). The extract obtained from $0.1 \mathrm{~g}$ of $C$. aquatica inhibited cress root and hypocotyl growth to 4.2 and $5.1 \%$ that of the control, respectively. It has been reported that aqueous methanol extracts of $C$. aquatica had the phytotoxic effect on several plant species including weed plants (Bich and Kato-Noguchi 2012). These results suggest that the extract of $C$. aquatica may have phytotoxic substances with allelopathic activity.

The extract of $C$. aquatica was then divided into aqueous and ethyl acetate fractions. Both fractions inhibited root and hypocotyl growth of cress seedlings (Figure 2). However, inhibitory activity of the ethyl acetate fraction was greater than that of the aqueous fraction. Thus, isolation of phytotoxic substances proceeded using the ethyl acetate fraction.

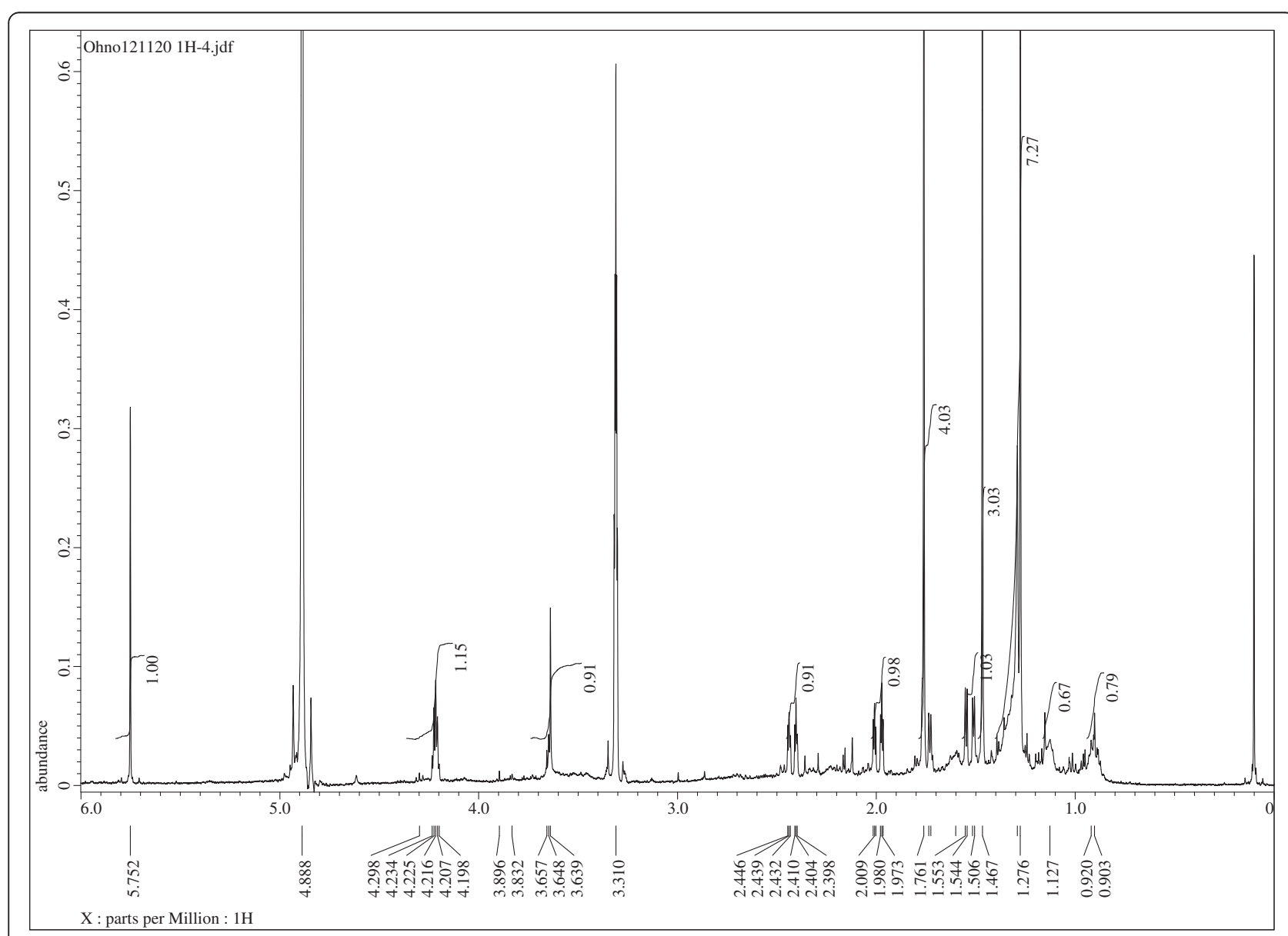

Figure $3^{1} \mathrm{H}$ NMR spectrum ( $400 \mathrm{MHz}, \mathrm{CD}_{3} \mathrm{OD}$, TMS as internal standard) of isolated compound. 


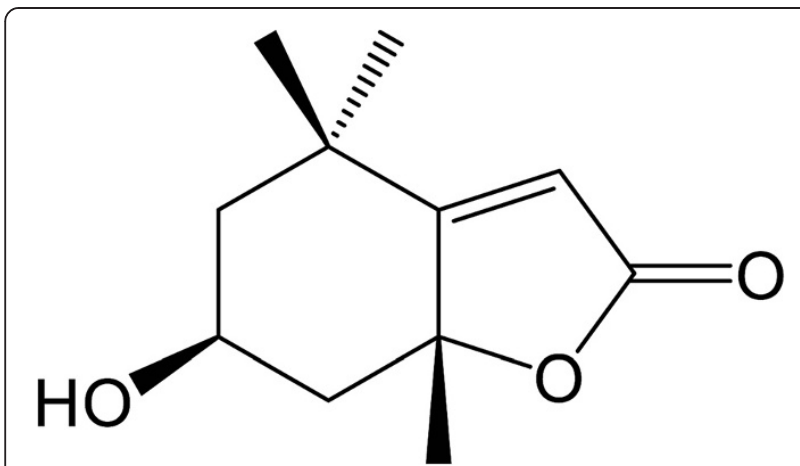

Figure 4 Chemical structure of loliolide.

Then, the ethyl acetate fraction of $C$. aquatica was separated on a silica gel column and the biological activity of all fractions was determined by the cress bioassay. The inhibitory activity was found in the fractions 5, 6 and 7 , obtained by elution with 60,70 and $80 \%$ ethyl acetate in $n$-hexane, respectively. The most active fraction 6 inhibited the growth of cress roots and hypocotyls by 7.2 and $13.8 \%$ that of control roots and hypocotyls, respectively.

\section{Identification of a phytotoxic substance}

The active fraction 6 , eluted with $70 \%$ ethyl acetate in $n$ hexane on the silica gel column, was further purified by Sephadex LH-20, reverse-phase $C_{18}$ and HPLC. The biological activity of all fractions after every separation step was determined by the cress bioassay. The most active fraction in each separation step was further purified and an active compound was isolated. The molecular formula of the active compound was determined to $\mathrm{C}_{11} \mathrm{H}_{20} \mathrm{O}_{3}$ by as suggested by HRESIMS at $m / z$ 197.1158 $[\mathrm{M}+\mathrm{H}]^{+}$ (calcd for $\mathrm{C}_{11} \mathrm{H}_{17} \mathrm{O}_{3}, 231.1361, \Delta=-2.0 \mathrm{mmu}$ ). The ${ }^{1} \mathrm{H}$ spectrum (400 MHz, CD ${ }_{3} \mathrm{OD}$, TMS as internal standard, Figure 3 ) of the compound showed $\delta_{\mathrm{H}} 5.70$ (s, $\left.1 \mathrm{H}, \mathrm{H} 7\right)$, 4.34 (m, $1 \mathrm{H}, \mathrm{H} 3), 2.46$ (ddd, $J=14.1,2.9,2.4 \mathrm{~Hz}, 1 \mathrm{H}$, H4b), 1.98 (ddd, $J=14.6,2.9,2.4 \mathrm{~Hz}, 1 \mathrm{H}, \mathrm{H} 2 \mathrm{~b}$ ), 1.79 (dd, $J=13.7,3.4 \mathrm{~Hz}, 1 \mathrm{H}, \mathrm{H} 4 \mathrm{a}), 1.79$ (s, $3 \mathrm{H}, \mathrm{H} 11), 1.54$ (dd, $J=$ 14.1, 3.4, Hz, $1 \mathrm{H}, \mathrm{H} 2 \mathrm{a}$ ), 1.47 (s, $3 \mathrm{H}, \mathrm{H} 9$ ), 1.28 (s, $3 \mathrm{H}$, $\mathrm{H} 10)$. The specific rotation of the compound was $[\alpha]_{\mathrm{D}}{ }^{22}=$ $-41^{\circ}\left(c=0.06, \mathrm{CHCl}_{3}\right)$. The compound was identified as 3dihydroxy-3,5,5-trimethylcyclohexylidene-4-acetic acid lactone (loliolide, Figure 4) by comparing those data with those in the literature (Hodges and Porte 1964; Valdés 1986; Kimura and Maki 2002).

Loliolide has been isolated from algal species such as Gracilaria lemaneiformis (Lu et al. 2011), Undaria pinnatifida (Kimura and Maki 2002) and Sargassum ringgoldianum (Yang et al. 2011). The compound has also isolated from terrestrial plant species, Salvia divinorum (Valdés 1986) and Eucommia ulmoides (Okada et al. 1994). However, this is the first report of the presence of loliolide in C. aquatica as a phytotoxic substance.

\section{Phytotoxic activity of loliolide}

Loliolide inhibited root and hypocotyl growth of cress at concentration greater than $0.03 \mu \mathrm{M}$ (Figure 5). At the concentration of $1 \mu \mathrm{M}$ of loliolide, cress roots and hypocotyls were inhibited by 7.8 and $5.8 \%$ that of control, respectively. The concentrations of loliolide required for $50 \%$ growth inhibition $\left(\mathrm{IC}_{50}\right)$ in the assay, as determined by a logistic regression analysis, were 0.18 and $0.15 \mu \mathrm{M}$ for cress roots and hypocotyls, respectively. In addition, loliolide was reported to have anti-algal activity ( $\mathrm{Lu}$ et al. 2011), immunosuppressive activity (Okada et al. 1994) and cytotoxic activity (Al-Mekhlafi et al. 2012).

Many of the phytotoxic substances from the invasive plants have been reported to have multiple effects,

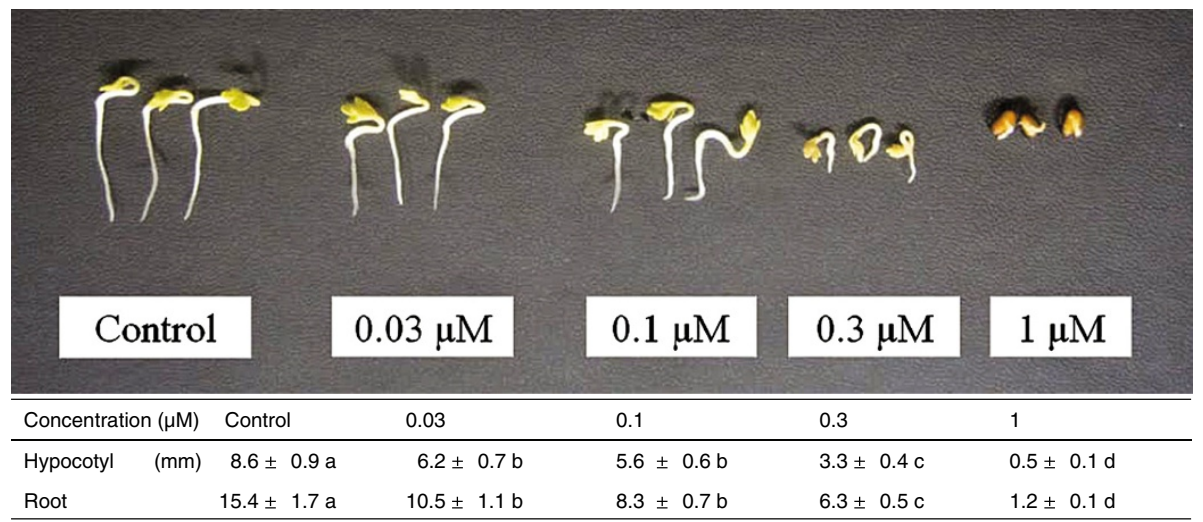

Figure 5 Effects of loliolide on the root and hypocotyl growth of cress seedlings. The different letters on the same organ indicate significant difference $(P<0.05)$ according to Duncan's multiple comparison tests. 
including anti-herbivore, anti-fungal, anti-microbial and allelopathic activities (Lockwood et al. 2001; Cappuccino and Arnason 2006). Therefore, those phytotoxic substances may enhance competitive ability and make the plants invasive. Several other observations also suggest that some invasive plant species are allelopathic and their allelopathic substances are more toxic against other plants in the invasive areas than in the original areas of the invasive plants (Cappuccino and Arnason 2006; Meiners et al. 2012). In addition, phytotoxic active substances in plants can be released into the neighboring environment, either as exudates from living plant tissues or by decomposition of plant residues (Bais et al. 2006; Bonanomi et al. 2006; Belz 2007).

\section{Conclusion}

A phytotoxic substance with allelopathic activity was isolated from $C$. aquatica extract. The chemical structure of the substance was determined as loliolide. $\mathrm{IC}_{50}$ value for cress roots and hypocotyls was 0.18 and $0.15 \mu \mathrm{M}$, respectively. These results suggest that loliolide may contribute to the allelopathic effect caused by the $C$. aquatica extract.

\section{Abbreviations \\ $\mathrm{IC}_{50}$ : Concentrations required for $50 \%$ growth inhibition; HRESI-MS: High- resolution electrospray ionization mass.}

\section{Competing interests}

The authors declare no conflict of interest.

\section{Authors' contributions}

TTNB is responsible for the whole experiments and wrote the article. HK-N is responsible for experimental design, result interpretation, made discussion and conclusion. Both authors read and approved the final manuscript.

\section{Acknowledgements}

TTNB was supported by the Ministry of Agriculture and Rural Development of Vietnam for her Ph. D program. The authors thank Dr. Oono O. and Dr. Suenaga K. (Keio University) for the chemical analysis and structural identification of the isolated compound, and Mr. Ho VT (Tri Viet Corp) for supplying plant material C. aquatica.

\section{Author details}

'Department of Applied Biological Science, Faculty of Agriculture, Kagawa University, Miki, Kagawa 761-0795, Japan. ${ }^{2}$ Present address: Department of Agriculture, The South College of Engineering and Agriculture, Cần Thơ, Vietnam.

Received: 30 April 2014 Accepted: 21 July 2014

Published: 12 August 2014

\section{References}

Al-Mekhlafi NA, Shaari K, Abas F, Kneer R, Jeyaraj EJ, Stanslas J, Yamamoto N, Honda T, Lajis NH (2012) Alkenylresorcinols and cytotoxic activity of the constituents isolated from Labisia pumila. Phytochemistry 80:42-49

Bais HP, Weir TL, Perry LG, Gilroy S, Vivanco JM (2006) The role of root exudates in rhizosphere interactions with plants and other organisms. Annu Rev Plant Biol 57:233-266

Baker JG (1913) Flora of Tropical Africa, vol 6 Part 1. Royal Botanic Gardens, Kew, p 14

Belz RG (2007) Allelopathy in crop/weed interactions - an update. Pest Manag Sci 63:308-326
Bich TTN, Kato-Noguchi H (2012) Allelopathic potential of four emergent macrophytes on the growth of terrestrial plant species. Int J Biol Sci Biol Tech 4:81-93

Bonanomi G, Sicurezza MG, Caporaso S, Esposito A, Mazzoleni S (2006) Phytotoxicity dynamics of decaying plant materials. New Phytol 169:571-578

Callaway RM, Aschehoug ET (2000) Invasive plants versus their new and old neighbors: a mechanism for exotic invasion. Science 290:521-523

Callaway RM, Ridenour WM (2004) Novel weapons: invasive success and the evolution of increased competitive ability. Front Ecol Environ 2:419-426

Cappuccino N, Arnason JT (2006) Novel chemistry of invasive exotic plants. Biol Lett 2:189-193

Cappuccino N, Carpenter D (2005) Invasive exotic plants suffer less herbivory than non-invasive plants. Biol Lett 1:435-458

Chengxu W, Mingxing Z, Xuhui C, Bo Q (2011) Review on allelopathy of exotic invasive plants. Procedia Engin 18:240-246

Hodges R, Porte AL (1964) The structure of loliolide: A terpene from Lolium perenne. Tetrahedron 20:1463-1467

Keane RM, Crawley ML (2002) Exotic plant invasions and the enemy release hypothesis. Trend Ecol Evol 17:164-170

Kimura J, Maki N (2002) New loliolide derivatives from the brown alga Undaria pinnatifida. J Nat Prod 65:57-58

Lockwood JL, Simberloff D, McKinney ML, Von Holle B (2001) How many, and which, plants will invade natural areas. Biol Inva 3:1-8

Lu H, Xie H, Gong Y, Wang Q, Yang Y (2011) Secondary metabolites from the seaweed Gracilaria lemaneiformis and their allelopathic effects on Skeletonema costatum. Biochem Syst Ecol 39:397-400

Mack RM (1996) Predicting the identity and fate of plant invaders: emergent and emerging approaches. Biol Conserv 78:107-121

Meiners SJ, Kong CH, Ladwig LM, Pisula NL, Lang KA (2012) Developing an ecological context for allelopathy. Plant Ecol 213:1861-1867

Mitchell CE, Power AG (2003) Release of invasive plants from fungal and viral pathogens. Nature 421:625-657

Okada N, Shirata K, Niwano M, Koshino H, Uramoto M (1994) Immuno-suppressive activity of a monoterpene from Eucommia ulmoides. Phytochemistry 37:281-282

Townsend CC (1988) Flora Zambesiaca vol 9 Part 1. Royal Botanic Gardens, Kew, p 28

Valdés LJ (1986) Loliolide from Salvia divinorum. J Nat Prod 49:171

Yang X, Kang M, Lee K, Kang S, Lee W, Jeon Y (2011) Antioxidant activity and cell protective effect of loliolide isolated from Sargassum ringgoldianum subsp. coreanum. Algae 26:201-208

doi:10.1186/s40529-014-0059-1

Cite this article as: Bich and Kato-Noguchi: Isolation and identification of a phytotoxic substance from the emergent macrophyte Centrostachys aquatica. Botanical Studies 2014 55:59.

\section{Submit your manuscript to a SpringerOpen ${ }^{\circ}$ journal and benefit from:}

- Convenient online submission

Rigorous peer review

- Immediate publication on acceptance

- Open access: articles freely available online

- High visibility within the field

- Retaining the copyright to your article

Submit your next manuscript at $\gg$ springeropen.com 